\title{
MALE FERTILITY IN UGANDA BANANA GERMPLASM
}

\author{
S.B. MUKASA and P.R. RUBAIHAYO \\ Crop Science Department, Faculty of Agriculture and Forestry, \\ Makerere University, \\ P. O. Box 7062, Kampala, Uganda.
}

(Received 16 April 1993, accepted 21 November, 1993)

\begin{abstract}
Identification of fertility levels in banana germplasm collection at Kabanyolo, Uganda, was conducted by dehiscing the anthers using a glass rod. The study involved 151 accessions. The quantity of pollen grains per anther was ranked 0-5; where 0 had no grains and 5 had abundant pollen grains. A correlation between pollen output and inflorescence characters revealed a positive relationship $(r=0.69, P \leq 0.01)$ to inflorescence diagnostic characters. A quantitative determination of pollen output per anther and percentage pollen viability based on starch test using the Heamocytometer method revealed that the amount of starch filled grains did not proportionally vary with the total pollen output. Pollen output varied from cultivar to cultivar. Most East African highland banana cultivars were found to have more pollen than the recently introduced banana cultivars. A few highland banana cultivars were non-polleniferous. The results indicate the relative potential of using various cultivars in hybridization and, anther and pollen culture programmes.
\end{abstract}

Key Words: Bananas, Heamocytometer, fertility, pollen.

\section{RÉSUMÉ}

L'identification du niveau de fertilité mâle dans le germplasm bananier à Kabanyolo, Ouganda, a été effectuee en fendant les anthères avec une tige de verre. Cette recherche comprend 151 accessions. La quantité de graines de pollen par anthère était classifiée de 0 à $5: 0$ où il n'y avait pas de graines et 5 où il y avait des graines en abondance. Une corrélation entre la production de pollen et les caractéristiques de l'inflorescence montrait des rapports positifs $(r=0,69 ; P \leq 0,01)$. Une détermination quantitative de la production de pollen par anthère et le pourcentage de viabilité de pollen, basée sur le teste d'amidon en utilisant l'hémocytomètre, a pu démontrer que la quantité de graines remplies d'amidon n'était pas proportionnelle à la production totale de pollen. La production de pollen varie d'un cultivar à l'autre. Il a été constaté que la plupart des cultivars des bananes d'altitude de l'Afrique de l'Est contenait plus de pollen que les cultivars récemment introduits. Quelques cultivars d'altitude ne produisaient pas de pollen du tout. Ces résultats-ci montrent le potentiel rélatif d'utiliser plusieurs cultivars dans les hybridisations et dans les programmes de la culture d'anthère ou de pollen.

Mots Clés: Bananaier, Heamocytometre, niveau de reproduction, pollen 


\section{INTRODUCTION}

Banana and plantain are a few of the tropical crops that have not been bred successfully due to their characteristic sterility; most of the presently cultivated varieties are natural selections. In banana breeding, wild and cultivated diploid clones have been used as male stock. In recent years, however, several cultivated triploids have also been utilised (Sathiamoorthy et al., 1984; Swennen and Vuylsteke, 1990). The utility of the triploids cultivars depends very much on the quantity and quality of pollen produced. Hence, pollen output is an important factor to be considered in the selection of male parents for breeding (Sathiamoorthy et al., 1990).

Triploids have been markedly known for being low in pollen production in comparison to diploids and tetraploids due to meiotic abnormality resulting in more of sterile pollen grains (Simmonds, 1966; Ramirez, 1990). Nevertheless, the presence of some viable pollen grains in the triploids indicates their possible use as male parents (Ramirez, 1990). East African highland bananas (AAA group), exhibit great diversity in Uganda to the extent that the country is recognised as a secondary diversity centre for the crop (Shepherd, 1957). Other groups of cultivars grown in Uganda include plantains (AAB group), Kisubi and Sukalindiizi (AB group) and, Musa-Kayinja and Kivuvu (ABB group) which are recent introductions into the area. Besides morphological characteristics, the uniqueness of East African Highland bananas could be portrayed in their potential to produce pollen.

The main objective of the work reported in this paper therefore was to evaluate pollen production potential of various banana cultivars in the Kabanyolo germplasm, and hence selection of potential male parents on the basis of pollen output and viability.

\section{MATERIALS AND METHODS}

Flowers between the 20th and 30th node of the male axis of the 151 banana clone collection at Kabanyolo banana field germplasm, at the Makerere University Agricultural Research Institute, were examined for presence of pollen by pressing a blunt glass rod on the anther towards the tip to expose the pollen grains. The quantity of pollen grains was ranked $0-5$; where $0=$ no pollen grain and $5=$ abundant pollen grains. Banana cultivars were also classified on the scale of 1-4 according to inflorescence features: prominent style remains, persistence of male flowers and bracts, a few scattered male flowers remaining and clean axis, respectively. A correlation was run for 134 East African highland banana cultivars between pollen output and inflorescence diagnostic characters.

The Heamocytometer method (Sathiamoorthy and Madhava Rao, 1980) was used to determine pollen output per anther and subsequently viability based on starch reserves in the grains. It was standardized with pollen of Gros Michel (AAA group) to determine the optimum sample size. From a male bud, five samples of 10 anthers each were collected just prior to dehiscence in vials containing $2.5 \mathrm{ml}$ iodine solution to test for grains containing starch. Three male buds for a given clone from different mats were used. The anthers were pressed gently using blunt glass rod, to encourage the anthers to dehisce properly. A drop of 'teepol', a wetting agent, was added to each sample to ensure good suspension of pollen grains. The contents were then shaken on an electric shaker for 1 minute to free the pollen grains from anthers. A drop of the pollen grain suspension was placed on each of two counting chambers of the 'Spencer Brightline Heamocytometer'. A total of 10 observations was made and the average number of pollen grain per square calculated. The average number of grains per square was multiplied by 2500 to give the quantity of pollen per anther (Sathiamoorthy and Madhava Rao, 1980). A Similar procedure was followed to determine the number of stained grains and hence viable grains based on the starch test. Viable pollen grains were calculated as a percentage of total pollen grains.

\section{RESULTS AND DISCUSSION}

The results of the pollen output for various banana cultivars in Kabanyolo germplasm are presented in Tables 1,2, 3 and 4 . The cultivars with a pollen count higher than 30,000 were rated highly polleniferous. These cultivars are comparable to Musa acuminata (Table 3). The majority of East African highland banana cultivars (AAA) showed higher pollen output than the recently introduced cultivars (AAA, AAB, ABB and AB), while a few 
TABLE 1. Total, viable and percent viable pollen output count per anther for some East African highland banana cultivars (AAA) in Kabanyolo banana germplasm.

\begin{tabular}{|c|c|c|c|c|}
\hline \multirow[b]{2}{*}{ Cultivar } & \multirow{2}{*}{$\begin{array}{l}\text { Inflorescence } \\
\text { character rank } \\
(1-4)\end{array}$} & \multicolumn{3}{|c|}{ Mean } \\
\hline & & Total & Viable & $\%$ Viable \\
\hline Siira white & 4 & 36280 & 13150 & 36.24 \\
\hline Nyabugere & 4 & 33640 & 11310 & 32.19 \\
\hline Entaga & 4 & 31180 & 8063 & 25.86 \\
\hline Bitambi & 4 & 30450 & 10430 & 34.24 \\
\hline Nakasabira & 4 & 30130 & 10900 & 36.18 \\
\hline Nambogo & 4 & 29160 & 10650 & 36.53 \\
\hline Mukite & 4 & 28840 & 9713 & 33.69 \\
\hline Mabira & 4 & 28210 & 10820 & 38.37 \\
\hline Murure & 4 & 27850 & 14450 & 51.88 \\
\hline Atwaliranyina & 4 & 27670 & 9625 & 34.78 \\
\hline Lwewunzika & 4 & 24530 & 7716 & 31.46 \\
\hline Kibalawo & 4 & 24120 & 9636 & 39.95 \\
\hline Bifusi & 4 & 24090 & 9788 & 40.68 \\
\hline Kisansa & 4 & 24060 & 8833 & 36.71 \\
\hline Nakhakki & 4 & 23928 & 9500 & 39.70 \\
\hline Nyakinika & 4 & 23875 & 11221 & 47.00 \\
\hline Entazinduka & 4 & 23830 & 9592 & 40.24 \\
\hline Namwezi & 4 & 23750 & 7967 & 33.52 \\
\hline Kaitabunyonyi & 3 & 23600 & 10502 & 44.50 \\
\hline Serunjogi & 4 & 23600 & 8024 & 34.00 \\
\hline Bukumu & 3 & 23500 & 10500 & 44.68 \\
\hline Nfuuka & 4 & 23450 & 11100 & 47.33 \\
\hline Enyabakazi & 4 & 23405 & 8157 & 34.85 \\
\hline Musakala & 4 & 23140 & 7344 & 31.72 \\
\hline Bandangeya & 4 & 23063 & 9380 & 40.67 \\
\hline Nakyetengu & 2 & 23040 & 7533 & 32.70 \\
\hline Nakitembe & 4 & 22920 & 6525 & 28.56 \\
\hline Mukazi aranda & 3 & 22795 & 9750 & 42.77 \\
\hline Endembezi & 4 & 22675 & 7843 & 34.59 \\
\hline Siira & 4 & 22600 & 10548 & 50.11 \\
\hline Ndibwabalangira & 4 & 21095 & 10328 & 49.00 \\
\hline Embururu & 4 & 21082 & 8335 & 39.54 \\
\hline Enzirabushera & 4 & 21070 & 10207 & 48.44 \\
\hline Enjagata & 2 & 20575 & 10457 & 50.83 \\
\hline Narugiri & 4 & 20575 & 8703 & 42.30 \\
\hline Toro & 2 & 20503 & 10275 & 50.11 \\
\hline Nandigobe & 2 & 20450 & 10300 & 50.37 \\
\hline Ntiti & 2 & 20428 & 10285 & 50.35 \\
\hline Kabucuragye & 3 & 20293 & 8320 & 41.00 \\
\hline Mugisu & 4 & 19980 & 9990 & 50.00 \\
\hline Entukura & 4 & 19700 & 6895 & 35.00 \\
\hline Enyeru & 4 & 19425 & 7382 & 38.00 \\
\hline Enyaruyonga & 4 & 19420 & 5917 & 30.49 \\
\hline Wansimirahi & 4 & 19345 & 8917 & 46.10 \\
\hline Karinga & 4 & 19300 & 8150 & 42.22 \\
\hline Kaasa & 4 & 19158 & 7433 & 38.80 \\
\hline Liyase & 4 & 19125 & 6770 & 35.40 \\
\hline Kifuba & 3 & 19000 & 6650 & 35.00 \\
\hline Rwamugongo & 4 & 18750 & 9075 & 48.40 \\
\hline Enkara & 4 & 18675 & 7200 & 38.55 \\
\hline Rwabakongo & 4 & 18500 & 9477 & 48.60 \\
\hline
\end{tabular}


Table 1. contd.

\begin{tabular}{|c|c|c|c|c|}
\hline \multirow[b]{2}{*}{ Cultivar } & \multirow{2}{*}{$\begin{array}{c}\text { Inflorescence } \\
\text { character rank } \\
(1-4)\end{array}$} & \multicolumn{3}{|c|}{ Mean } \\
\hline & & Total & Viable & $\%$ Viable \\
\hline Kulwoni & 4 & 18100 & 6878 & 38.00 \\
\hline Engambani & 4 & 17500 & 7000 & 40.00 \\
\hline Imbululu & 3 & 17450 & 6806 & 39.00 \\
\hline Kafunzi & 2 & 17295 & 6157 & 35.60 \\
\hline Enzinga & 4 & 16650 & 5661 & 34.00 \\
\hline Nakangu & 2 & 16532 & 6050 & 36.60 \\
\hline Nakamali & 2 & 16525 & 5950 & 36.01 \\
\hline Nabusa & 4 & 16230 & 7883 & 48.57 \\
\hline Oruhuna & 2 & 16000 & 5232 & 32.70 \\
\hline Enywamaizi kabura & 3 & 15925 & 7850 & 49.29 \\
\hline Muvubo & 3 & 15900 & 7656 & 48.00 \\
\hline Nasuuna & 4 & 15875 & 6350 & 40.00 \\
\hline Kaitaluganda & 4 & 15725 & 7750 & 49.28 \\
\hline Mbwazirume & 1 & 15220 & 3820 & 25.06 \\
\hline Salalugazi & 2 & 14830 & 6000 & 40.76 \\
\hline Kasenene & 4 & 12810 & 4614 & 36.12 \\
\hline Wekanga & 2 & 12750 & 4998 & 39.20 \\
\hline Khabusi & 4 & 12730 & 5200 & 41.25 \\
\hline Kitetengwa & 2 & 12675 & 5700 & 44.97 \\
\hline Naminwe-2 & 3 & 10150 & 4667 & 45.99 \\
\hline Kisugunu & 1 & 9900 & 1980 & 20.00 \\
\hline Bikowekowe & 1 & 9460 & 1562 & 16.51 \\
\hline Nakawere & 1 & 9150 & 5075 & 55.46 \\
\hline Entaragaza & 1 & 9032 & 1997 & 22.11 \\
\hline Namaliga & 2 & 8917 & 1517 & 17.07 \\
\hline Bwara & 1 & 8525 & 1412 & 16.56 \\
\hline Enshakara & 2 & 7750 & 2325 & 30.00 \\
\hline Luvuta & 1 & 7000 & 1750 & 25.00 \\
\hline Entaragaza & 1 & 6750 & 2300 & 34.00 \\
\hline Lisindalo & 1 & 5325 & 1180 & 22.16 \\
\hline Kibuzi & 1 & 0 & 0 & 0 \\
\hline Rwakashita & 1 & 0 & 0 & 0 \\
\hline Envarutere & 1 & 0 & 0 & 0 \\
\hline Oruhuna beer & 1 & 0 & 0 & 0 \\
\hline Endirira & $N^{a}$ & 0 & 0 & 0 \\
\hline$\overline{\text { Grand Mean }}$ & & 21163.2 & 4150.9 & - \\
\hline $\operatorname{LSD}(P=0.05)$ & & 1942.2 & 927.2 & - \\
\hline
\end{tabular}

ano male bud

like Kibuzi, Rwakashita, Enyarutere, Oruhuna (Beer) were found to be completely nonpolleniferous. Elsewhere, triploid bananas have been noted to produce less pollen than the cultivated and wild diploid cultivars (Sathiamoorthy and Madhava Rao, 1980). The East African highland bananas, however, have been observed to produce more pollen than their related genotypes, triploid AAA, as reported by Sathiamoorthy and Madhava Rao (1980). This is illustrated further by the more world-wide grown triploid AAA cultivars like Gros Michel (Bogoya),
Red banana (Bogoya red) and Dwarf Cavendish by being generally lower pollen producers (Table 2) than East African Highland banana cultivars.

Among East African highland bananas, the cultivar Murure (Table 1) showed the highest amount of starch filled pollen grains despite the fact that it had a lower total pollen output than the highly polleniferous cultivars. It also showed the highest percentage of viable pollen grains despite the low total pollen output. Musa-Kayinja (Table 4), a non East African highland banana, had the least total pollen output, but the highest percentage 
viable grains. Thus, the amount of starch filled grains does not vary proportionally with the total pollen output.

A tendency of low pollen production has been observed with cultivars having the $B$ genome ( $A B, A A B$ and $A B B)$. For example, Nakatansese (French plantain AAB), Sukalindiizi (Lady's finger AB), Kivuvu (Bluggoe ABB) and MusaKayinja (Pisang awak ABB) showed low pollen output suggesting that cultivars of a bispecific origin have more difficulties in pollen production than the AAA genome. Majaga (AAB) did not produce any pollen. Pollen production was very low in diploid cultivars, and all the diploids except Sukalindiizi, which had the second least output of the polleniferous cultivars, did not produce any pollen (Table 3). Hence, pollen production was highest in the East African Highland bananas followed by AAA (recently introduced), $A A B, A B B$ and least with $A B$ genome (Tables 1,2 and 4). It should be noted that all the diploids under investigation were bispecific hybrids $(A B)$ and pollen output values from literature are for $\mathrm{AA}$ or $\mathrm{BB}$ diploid cultivars (Sathiamoorthy and Madhava Rao, 1980). This could explain the effect of structural heterozygosity on pollen production in Musa spp. (Ramirez, 1990).

Absence of the male bud has been observed on one East African highland banana cultivar, Endirira, and two plantains: Horn plantain (AAB) and Manjaya (False horn plantain AAB). This is a feature which inhibits the use of these cultivars as pollen parents. Fortunately, plantains (AAB) have been reported to switch from one form of the plantain to another (Swennen and Vuylsteke,
1990) with a male inflorescence. This switching has been observed by the authors on Horn plantain in Kabanyolo banana germplasm.

Grouping of banana cultivars according to pollen output seems to have no clear taxonomic implication. This could be due to wide morphological and biochemical variations within a cultivar that arise from mutations. Mutations have been observed in the inflorescence characters like change in persistence of male bud. However, inflorescence variations are less frequent than the observable pigmentation changes in the pseudostem and leaves. Close similarity of inflorescence parts may not indicate short genetic distances between cultivars. For example Endirira cultivar which is an East African highland banana (AAA) is morphologically and genetically different from Manjaya (False horn plantain AAB) but their terminal inflorescences are similar. They both loose their male buds soon after the last filled fingers. Similarly, on the basis of pollen output different cultivars like Nakyetengu with persistent male flowers and Musakala which is a very tall cultivar with a clean male rachis are in the same group.

Known mutants have shown significantly different pollen production levels from the original cultivars; Kivuvu and its mutant, Kidhozi are an exception. These two cultivars are similar except for waxiness of the entire plant. For example, Oruhuna (Table 1) and Sukalindiizi (Table 3) are polleniferous while their mutants Oruhuna beer and Sukalindiizi red, respectively, have no pollen. Likewise Siira white, a mutant of Siira, was noted to be significantly more polleniferous than Siira (Table 1). Kizungu red and its mutant Kizungu

TABLE 2. Total, viable and percent viable pollen output count per anther for triploid (AAA) banana cultivars in Kabanyolo banana germplasm.

\begin{tabular}{|c|c|c|c|c|c|}
\hline \multirow[b]{2}{*}{ Cultivar } & \multirow{2}{*}{$\begin{array}{l}\text { Inflorescence } \\
\text { character rank } \\
(1-4)\end{array}$} & \multirow[b]{2}{*}{ Total } & \multicolumn{2}{|c|}{ Mean } & \multirow{2}{*}{$\begin{array}{l}\text { Cited from } \\
\text { Literature }^{\mathrm{a}}\end{array}$} \\
\hline & & & Viable & \%viable & \\
\hline Gros Michelb & 4 & 11250 & 5351 & 47.55 & 10500 \\
\hline Red bananac & 3 & 10100 & 4808 & 47.61 & 7500 \\
\hline Kizungu red & 3 & 10033 & 4800 & 47.80 & \\
\hline Kizungu white & 3 & 9933 & 4642 & 46.72 & \\
\hline Dwarf Cavendish & 2 & 5851 & 1146 & 19.59 & 5050 \\
\hline $\operatorname{LSD}(P=0.05)$ & & 184.0 & 302.5 & - & - \\
\hline
\end{tabular}

aSathiamoorthy and Madhava (1980)

bGros Michel (Bogoya)

'Red banana (Bogoya red) 
TABLE 3. Total, viable and percent viable pollen output count per anther for diploid banana cultivars $(A B)$ in Kabanyolo banana germplasm.

\begin{tabular}{|c|c|c|c|c|c|}
\hline \multirow[b]{2}{*}{ Cultivar } & \multirow{2}{*}{$\begin{array}{c}\text { Inflorescence } \\
\text { character rank } \\
(1-4)\end{array}$} & \multirow[b]{2}{*}{ Total } & \multicolumn{2}{|c|}{ Mean } & \multirow{2}{*}{$\begin{array}{l}\text { Cited from } \\
\text { Literature }\end{array}$} \\
\hline & & & Viable & \%viable & \\
\hline Musa balbisiana $(\mathrm{BB})^{\mathrm{b}}$ & & - & - & - & 47140.0 \\
\hline Musa acuminata $(\mathrm{AA})^{\mathrm{b}}$ & & - & - & - & 40119.0 \\
\hline Sukalindizi $(A B)$ & 4 & 2417 & 810 & 33.50 & \\
\hline Kisubi $(A B)$ & 4 & 0 & 0 & 0 & \\
\hline Ndiziwemiti (AB) & 4 & 0 & 0 & 0 & \\
\hline Sukalindiizi red (AB) & 4 & 0 & 0 & 0 & \\
\hline
\end{tabular}

asathiamoorthy and Madhava (1980)

bMusa balbisiana (BB) and Musa acuminata (AA) are non existent in Uganda banana germplasm collection. Diploids are represented by only 4 bispecific hybrids.

TABLE 4. Total, viable and percent viable pollen output count per anther for triploid (AAB and $A B B$ ) banana cultivars in Kabanyolo banana germplasm.

\begin{tabular}{|c|c|c|c|c|c|}
\hline \multirow[b]{2}{*}{ Cultivar } & \multirow{2}{*}{$\begin{array}{c}\text { Inflorescence } \\
\text { character rank } \\
(1-4)\end{array}$} & \multirow[b]{2}{*}{ Total } & \multicolumn{2}{|c|}{ Mean } & \multirow{2}{*}{$\begin{array}{l}\text { Cited from } \\
\text { Literature }\end{array}$} \\
\hline & & & Viable & $\%$ viable & \\
\hline Nakatansese (AAB) & 1 & 4577 & 1021 & 22.33 & $4833^{b}$ \\
\hline Gonja red (AAB) & 2 & 4460 & 1032 & 23.15 & \\
\hline Kivuvu $(\mathrm{ABB})^{\mathrm{e}}$ & 4 & 3984 & 1154 & 28.98 & $4812^{c}$ \\
\hline Kidhozi (ABB) & 4 & 2925 & 878 & 30.00 & \\
\hline Musa-Kayinja (ABB) ${ }^{f}$ & 4 & 850 & 466 & 55.03 & \\
\hline Majaga $(A A B)$ & 2 & 0 & 0 & 0 & \\
\hline Horn plantain (AAB) & $\mathrm{NA}^{\mathrm{a}}$ & 0 & 0 & 0 & \\
\hline Manjaya (False horn) & $\mathrm{NA}^{\mathrm{a}}$ & 0 & 0 & 0 & \\
\hline$(P=0.05)$ & $\bar{\cdot}$ & 241.2 & 102.8 & - & - \\
\hline
\end{tabular}

${ }^{a}$ no male bud.

${ }^{b}$ mean for pollen output of triploids- AAB group (Plantains).

cmean for pollen output of triploids- ABB group.

oMusa-Kayinja (Pisang awak)

fKivuvu (Bluggoe)

white which are dessert bananas differ only in the level of red pigmentation but have the same level of pollen output. These observation indicate that pollen output varies widely between East African highland bananas cultivars and their mutants. However, some cultivar believed to be synonymous, like Nandigobe, Ntiti, Enjagata and Toro, Ndibwabangira and Enzirabushera, and Serunjogi and Namwezi, showed similar pollen production levels (Table 1 ). These results complicate the hypothesis that pollen output together with morphological characters can be used to determine genetic closeness in Musa ssp.

The inflorescence characters and pollen output were subjected to correlation analysis. Pollen output was positively related to the inflorescence characters ( $r=0.69)$. The R-Square showed that independent variable, inflorescence characters, contribute $58.4 \%$ to the dependent variable (pollen output rank). There are, however, exceptions. For example, Shombobureku is non-polleniferous but has inflorescence character rank 3 and a few scattered male flowers, which depict high pollen output. Although the male fertility performance measured as total or mean viable pollen production varies from cultivar to cultivar, the results indicate the relative potential of using various cultivars in hybridization and, anther and pollen culture programmes.

The fact that success in hybridisation of plantains (AAB) has been registered (Swennen and Vulysteke, 1990), the prospects of 
hybridisation in East African highland bananas which have shown high male fertility levels are encouraging. However, Sathiamoorthy et al. (1984) noted that seed set depends not only upon male parent but primarily on the fertility level of the female parent. Therefore, there is a need to evaluate female fertility of the East African highland banana germplasm.

\section{ACKNOWLEDGEMENTS}

The research work reported in this paper was conducted under the Banana Based Cropping Systems Research Programme supported by the Rockefeller Foundation. The authors sincerely wish to express their gratitude to the Foundation for all the financial assistance.

\section{REFERENCES}

Bakry, F., Horry, J.P., Teisson, C., Tezenas du Montcel, H. and Ganry, J. 1990. Genetic improvement of Bananas at CIRAD/IRFA. In FRUITS, Institute de recherches sur les fruits et Agrume. English Edition. Numero Special, 1990.

Purseglove, J.W. 1988. (Ed.) Tropical Crops: Monocotyledons. Longman/ELBS, London pp. 345-377.

Ramirez, D.A. 1990. A cytological survey of Philippine Bananas: In Jarret, R.L. (Ed.) Identification of Genetic Diversityin the Genus Musa: proceedings of an international workshop held at Los Banos, Philippines, 510 September 1988. p. 92.

Sathiamoorthy, S. and Madhava Rao, V. N. 1980. Pollen production in relation to genome and ploidy in banana clones: Proceedings of National Seminar, Banana Production Technology, Tamil Nadu Agricultural University, Coimbatore, 1980. p. 46-49.

Sathiamoorthy, S., Madhava, V.N. and Bhakthavatsalu, C. 1984. Banana Germplasm and Breeding in India. In Current problems on fruits and vegetables. $121 \mathrm{pp}$.

Shepherd, K. 1957. Banana cultivars in East Africa. Tropical Agriculture Trinidad 34 (4): 227286.

Simmonds, N.W. 1962. Evolution of Bananas. Longman. London

Simmonds, N.W. 1966. Bananas. Tropical Agriculture Series, Longmans. 2ndEd.London and New York, Longman. 512 pp.

Swennen, R. and Vuylsteke, D. 1990. Aspects of plantain breeding at IITA. In Fullerton, R. A., Stover, R.H. (Eds.) Sigatoka LeafspotDisease of Bananas: Proceedings of an international workshop held at San Jose, Costa Rica, March 28-April 1, 1989. 374 pp.

Valmayor, R.V., Silayoi, B., Jamaluddin, S.H., Kusuno, S., Espino, R.R.C. and Pascua, O.C. 1991. Banana classification and commercial cultivars in Southeast Asia. Los Banos, Laguna: PCARRD, 1991. Info. Bulletin 24 : $1-2$. 
